\title{
Food Insecure Household Coping Strategies: The Case of a Low Income Neighborhood in South Africa
}

\author{
Wynand C. J. Grobler \\ North West University (Vaal Triangle Campus), Vanderbijpark, 1900, South Africa, \\ Email: Wynand.Grobler@nwu.ac.za
}

Doi:10.5901/mjss.2014.v5n13p100

\begin{abstract}
Food security can be defined as a state in which all people in a household have at all times have both physical and economic access to sufficient food to meet their dietary needs for a productive and healthy life. In the last decade household food insecurity in rural and urban areas has been associated with several negative health and nutrition outcomes. The questions which arise are thus: How do food insecure households in urban areas cope with food insecurity? To what extent do they limit food intake as a coping strategy? A quantitative research method was deployed and a stratified random sample of 300 was used to collect data in Bophelong, a low income neighborhood in South Africa. The Coping Strategies Index (CSI) and Household Food Insecurity Access Scale (HFIAS) were used to measure the food security status of the households. The CSI Raw Score and HFIAS Score was then calculated and the correlation with different coping strategies determined. The study found that households did use coping strategies in order to mitigate shortages of food. Additionally, it revealed that as CSI scores/HFIAS scores increased, the reliance on consumption coping strategies by households increased. This indicates a high level of food insecurity. Spearman's correlation indicates that food limiting strategies correlated significantly with the cumulative CSI scores and HFIAS scores of households. The study concluded that urbanization and the resultant effects of unemployment, poverty, and ultimately, food insecurity, remain a challenge to policymakers. There may be an urgent need for the development of a more comprehensive food security strategy, focusing on urban as well as rural areas in South Africa.
\end{abstract}

Keywords: Food Security, coping Strategies, urban food insecure, food insecurity

\section{Introduction}

Food security is defined by the United States Agency for International Development (USAID, 1992) as a state in which all people in a household have both physical and economic access to sufficient food to meet dietary needs for a productive and healthy life. Food security, in this context, comprises the availability of and access to food, as well as the utilization of food. South Africa can be considered as food secure at the national level, but recent studies indicate that there is food insecurity at the household level (Manyamba, Hendriks, Chilonda and Musaba, 2012; Kirkland, Kemp, Hunter, and Twine, 2011). In the 1990s researchers indicated that poverty and food insecurity will probably shift to urban areas (UNICEF, 1994; De Haan, 1997; Moser, 1996). In this regard, South Africa was not an exception as a significant number of households in low income urban areas in South Africa are food insecure (Oldewage-Theron, Dicks, and Napier, 2006). Although it is well-documented that there was progress in eradicating food insecurity in South Africa (Sampson et al, 2004; Booysen, 2004), households in low income urban areas in South Africa are still food insecure. The Income and Expenditure Survey of 1995 (STATS SA, 1995) found an urban food poverty rate of 27 percent and a rural poverty rate of 54 percent amongst households in South Africa. In 2008 the South African Social Attitude Survey found 20.5 percent urban food insecurity and 33.1 percent rural food insecurity (HSRC, 2008).

The poor living in urban areas may become increasingly food insecure as a result of demographic and economic challenges associated with urbanization (Ravallion, 2002). Access to food and expenditure on food may depend on whether households in urban areas have enough income to purchase food (Behrman \& Deolher, 1988; Hoyos \& Meveden, 2009) In this regard, researchers indicated that food availability may not be the only condition for food insecurity, especially if households lack financial or productive resources to acquire food (Migotto, Gero and Kathleen, 2006; Adato \& Basset, 2012; Miller, Tsoka and Reichert, 2011; Manyamba et al, 2012). The implication of this is that food insecurity in urban areas may require a different approach to eradicate urban food insecurity.

The questions that arise against this background are thus: How do food insecure households survive in urban areas? What strategies do households use to mitigate food shortages? To what extent do they limit food intake as a coping strategy in urban low income areas? Therefore, the objectives in this study were, firstly, to determine the extent of food insecurity in a low income neighborhood, and, secondly, to analyze the different coping strategies as reported by households. The research aims to expand the general understanding of food insecurity at the household level in urban 
settings.

\section{Literature Review}

The concept "food security", together with the understanding of poverty, has evolved since the World Food Conference in 1974, and the debate surrounding food insecurity has shifted to the household level (Maxwell, 1996). The measurement of food insecurity presents many challenges. Assessment methodologies differ from qualitative to quantitative methods (Migotto et al, 2006) and several studies have provided insight into the experience of households with regard to food insecurity. This includes feelings of anxiety over food shortages, perceptions that food is of insufficient quantity, perceptions that food is of insufficient quality, reported reductions of food intake by households, reported consequences of reduced food intake by households, and negative feelings surrounding the socially unacceptable means to obtain food (Radimer, Olson, and Campbell, 1990; Radimer, Olson, Greene, Cambell and Habicht, 1992).

To measure food insecurity, Migotto et al, (2006) identifies five general types of methodologies namely, measuring undernourishment, measuring food intake, measuring nutritional status, measuring food access in terms of income, and measuring vulnerability. In this regard, the Funded Food and Nutritional Technical Assistance (FANTA) project established by the United States Agency for International Development (USAID), has developed the Household Food Insecurity Access Scale (HFIAS), which has been validated cross-culturally (Deitchler, Baalard, Swindale and Coates, 2010). In this study it is the intention to use the HFIAS as part of the analyses to identify food insecure households and to determine the correlation coefficient with coping strategies used by households.

Coping Strategies (CS) are defined by Snell and Staring (2001) as all strategically selected acts that individuals and households in a poor socio-economic position use to restrict their expenses or earn extra income to enable them to pay for basic necessities and not fall too far behind society's level of welfare. Strategically selected coping acts can be divided into "coping strategies" (mechanisms to deal with a short-term insufficiency of food) and "adaptive strategies" (long term changes in the way which households and individuals acquire sufficient food or income) (Davies, 1993). Davies (1993) distinguishes further between "income soothing" and "consumption soothing" strategies. Income soothing strategies attempt to reduce food insecurity through income diversification, and consumption soothing strategies attempt to limit consumption of members of a household. Coping strategies used as a measure/indicator of household food security were previously used by other researchers (Christaensen and Boisvert, 2000; Maxwell, Ahiadeke, Levin, ArmarKlemesu, Zakariah, and Lamptey, 1999). A number of household level strategies for dealing with insufficient food were identified by other researchers, which include: short term dietary changes; reducing or rationing consumption; altering household consumption; altering intra-household distribution of food; increased use of credit; increased reliance on wild food; alteration of crop and livestock production patterns; and sales of assets (Corbett, 1988; Frankenberg, 1992; Davies, 1993).

This study is based on the coping strategies proposed by Maxwell and Caldwell (2008). A similar study done by Mjonono, Ngidi and Hendriks (2009) indicated that households did indeed employ coping strategies to mitigate food shortages in rural areas in South Africa. Maxwell and Caldwell (2008) distinguish between immediate and short term alteration of consumption patterns and longer term alterations of income earnings or food production patterns. Research indicated that short term consumption strategies may be an accurate indicator of acute food insecurity and can also be seen as predictive of how households perceive the future in terms of food insecurity of the household (Christaensen and Boisvert, 2000; Coates, Frongillo, Rogers, Webb, Wilde and Houser, 2006; Maxwell et al, 1999).

\section{Research Methodology}

\subsection{Background of the Study Area}

Data for this study were collected in Bophelong, a low income neighborhood in the Vaal area of Southern Gauteng, a province in South Africa. The total number of residents living in Bophelong is estimated at $37 \mathbf{7 7 9}$, with an estimated number of households of 12352 (STATS SA, 2011). The unemployment rate in the Vaal area increased from 33.0 percent in 1991 to 50.4 percent in 2000, and 48.4 percent in 2010, indicating that almost half of the economically active population (those willing and able to work) of the Vaal were unemployed in 2010. In 2010, 39.3 percent of all households in the Vaal were living below their respective poverty lines (96 351 households) with an average shortfall of R615 per household per month (Slabbert and Grobler, 2011).

A study done by Slabbert and Sekhampu (2009) indicated that 66.3 percent of the residents of Bophelong are poor. Bophelong were chosen for this study because of the high unemployment and poverty rate in the area. 


\subsection{Methodology}

\subsubsection{Sample and Data collection}

A quantitative research method was used and a random sample of 300 households was interviewed using the face-toface method, during September 2013. All fieldworkers were trained and were able to explain the questions to respondents in their home languages. The questionnaire was developed to gather information on socio-economic status of households, food security and coping strategies used. The statistical package, SPSS Version 21 was used to do the statistical analyses.

\subsubsection{Measuring Instruments}

The validated Household Food Insecurity Access Scale (HFIAS) and validated Coping Strategy Index (CSI) were used as instruments. The Household Food Insecurity Access Scale (HFIAS) was used to determine food security status of households. The HFIAS, a nine-item food insecurity scale developed by the USAID FANTA project measures anxiety about food supply, followed by questions about food quality, questions on food quantity, and, lastly, questions on going to sleep hungry or going all day and night without eating (Deitchler et al, 2010). The HFIAS score is then calculated as a continuous measure of the degree of food insecurity (access) in the household in the past four weeks (30 days). The score adds up to a maximum score of 27 for a household if food insecure and a minimum of 0 when the household is food secure.

The Coping Strategy Index (CSI) proposed by Maxwell and Caldwell (2008), adapted for South African urban areas, was used to identify the coping strategies used by households in the low income neighborhood. The CSI calculation includes four distinct steps, namely: identify the different coping strategy behaviors, determine the frequency of strategies used, determine the severity and weighting of strategies used and, finally, scoring/combining of frequencies and severity. The frequency is measured ranging from "never' (0) to "every day" (7), and the severity from "most severe" (4) to "least severe" (1). The CSI raw scores, the more food insecure the household is. Spearman's correlation coefficients were used to calculate the correlation between HFIAS Score/ CSI Score and coping strategies used by the different households. In other words, which coping strategies are used when the HFIAS Score or CSI Score increases for an individual household?

\section{Results and Discussion}

The objective of this study was to determine the food insecurity status of households in a low income urban neighborhood and to identify the coping strategies used to mitigate food shortages. An overview of descriptive statistics of the sample is given in Table 1. The minimum household size in the sample is 1 and the maximum household size is 17 , with a mean household size of 4.35 members per household. The minimum age of the head of a household is 18 and the maximum age of a head of a household 99, with a mean age of the head of the household of 49.20 years. The minimum years of education of the head of the household are 2 years and the maximum number of years of schooling is 17, with a mean number of years of schooling of the head of the household is 10.20 years. The minimum income of a household in the sample is R 100.00 and the maximum income R 16000.00 per household, with a mean income per household of R 3 210.07. The mean HFIAS Score is 12.17 and the maximum score 27. The minimum CSI Score is 0 , and the maximum CSI Score of a household is 118 with a mean of 26.26 .

Table 1: Descriptive statistics of Sample $(\mathrm{N}=300)$

\begin{tabular}{|l|c|c|c|c|c|}
\hline \multicolumn{1}{|c|}{ Variable } & N & Minimum & Maximum & Mean & Standard Deviation \\
\hline HH Size & 300 & 1 & 17 & 4.35 & 2.05 \\
\hline Age Head & 300 & 18 & 99 & 49.20 & 13.21 \\
\hline Education Head & 300 & 2 & 17 & 10.20 & 4.99 \\
\hline Total Income & 300 & 100 & 16000 & 3210.07 & 3033.81 \\
\hline HFIAS Score & 300 & 0 & 27 & 12.17 & 6.85 \\
\hline CSI Score & 300 & 0 & 118 & 23.53 & 26.26 \\
\hline
\end{tabular}

The HFIAS Scale was used to identify the food insecure households. The categories of food insecurity of households are shown in Table 2. It is shown in table 2 that 56.67 percent of the households in the sample are severely food insecure. 
Table 2: Food security status of grant recipient households

\begin{tabular}{|l|c|c|}
\hline \multicolumn{1}{|c|}{ Food Insecurity Category } & \multicolumn{2}{c|}{ Total } \\
\hline Food secure & Number & $\%$ \\
\hline Mild food insecure & 27 & 9.00 \\
\hline Moderately food insecure & 28 & 9.33 \\
\hline Severe food insecure & 75 & 25.00 \\
\hline \multicolumn{1}{|c|}{ Total } & 170 & 56.67 \\
\hline \multicolumn{2}{|c|}{} \\
\hline
\end{tabular}

The survival strategies used by households in the sample is shown in Table 3, and visually depicted in Figure 1. Households in the sample mostly sourced their food from purchases. Only 15.2 percent of the households indicated that they maintain a food garden. The coping strategy indicated by most of the households in the sample is to rely on less expensive commodities, followed by buying only necessities, sticking to budget (dietary change strategies), limit portions, and to skip meals at mealtime (rationing strategies). This is in line with the findings of Oldewage-Theron et al, (2006), in an urban area.

A total of 166 households or 54.6 percent of households in the sample indicated that they rely on less expensive food more than once a week. A total of 56 households (19.0 percent) indicated that they skip meals more than once a week, while 4.4 percent of households skip meals more than three times a week. A total of 30.9 percent of the households in the sample (91 households) limited portions size of meals more than once a week. A total of 40 households or 13.6 percent of households in the sample restricted consumption of adults in order for small children to eat at least once a week.

Only 18 households or 6.1 percent of the households in the sample sent households members to beg for food, etc. A total number of 85 households or 28.8 percent of households borrowed food or rely on help from family or friends. In terms of food rationing strategies (consumption soothing), 126 households in the sample (37.7 percent) limited portion size at meal times and 90 households (28.8 percent) skip meals.

Table 3: Survival strategies used by households in Bophelong

\begin{tabular}{|c|l|c|c|c|c|c|}
\hline & \multicolumn{5}{|c|}{ Have you adopted any of the following means for survival } \\
\hline & \multicolumn{1}{|c|}{} & Daily & $3-6$ days / week & $1-2$ days / week & Not more than once/ week & Never happened \\
\hline 1 & Rely on less expensive commodities. & $32(10.8)$ & $21(7.1)$ & $108(36.6)$ & $20(6.8)$ & $114(38.6)$ \\
\hline 2 & Purchased food on credit & $1(0.3)$ & $12(4.1)$ & $63(21.4)$ & $14(4.7)$ & $205(69.5)$ \\
\hline 3 & Skip meals & $2(0.7)$ & $11(3.7)$ & $43(14.6)$ & $29(9.8)$ & $210(71.2)$ \\
\hline 4 & Limited portion size at meal times & $13(4.4)$ & $22(7.5)$ & $56(19.0)$ & $20(6.8)$ & $184(62.4)$ \\
\hline 5 & Buy necessities & $20(6.8)$ & $20(6.8)$ & $123(41.7)$ & $12(4.1)$ & $120(40.7)$ \\
\hline 6 & Stick to budget & $7(2.4)$ & $16(5.4)$ & $88(29.8)$ & $21(7.1)$ & $163(55.3)$ \\
\hline 7 & Maintain a food garden & $2(0.7)$ & $1(0.3)$ & $42(14.2)$ & $12(4.1)$ & $238(80.7)$ \\
\hline 8 & $\begin{array}{l}\text { Borrowed food, or rely on help from a } \\
\text { friend or relative }\end{array}$ & $1(0.3)$ & $7(2.4)$ & $77(26.1)$ & $9(3.1)$ & $201(68.1)$ \\
\hline 9 & $\begin{array}{l}\text { Sent household members to eat } \\
\text { elsewhere }\end{array}$ & $0(0)$ & $3(1.0)$ & $19(6.4)$ & $8(2.7)$ & $265(89.8)$ \\
\hline 10 & $\begin{array}{l}\text { Restricted consumption of adults in } \\
\text { order for small children to eat }\end{array}$ & $7(2.4)$ & $11(3.7)$ & $22(7.5)$ & $12(4.1)$ & $243(82.4)$ \\
\hline 11 & Sent households members to beg & $0(0)$ & $0(0)$ & $18(6.1)$ & $6(2.0)$ & $271(91.9)$ \\
\hline 12 & Gathered wild vegetables & $1(0.3)$ & $2(0.7)$ & $25(8.5)$ & $7(2.4)$ & $260(88.1)$ \\
\hline
\end{tabular}

Percentages in brackets

Figure 1 shows the survival strategies used by households in the sample at least once a week and three times and more per week. 
Figure 1: Survival strategies used by households 3 days and more per week or at least once a week (\%)

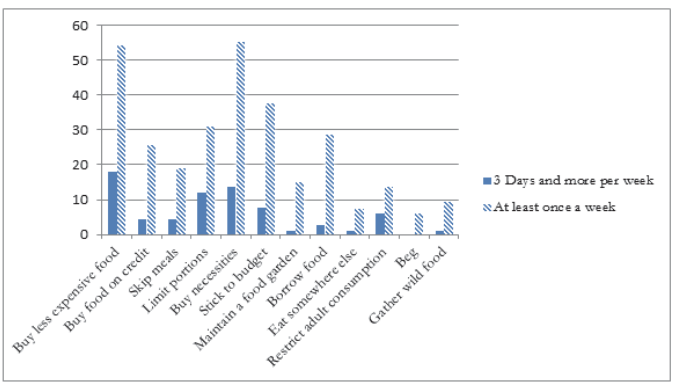

When comparing the mean of the different coping strategies reported by households, the highest mean of 1.9153 days is indicated for relying on less expensive food, followed by 1.6881 for buying necessities, and 1.1051 for sticking to budget. The lowest mean was recorded for members sent to beg (0.1424), sending members to eat elsewhere (0.2068), and maintaining a food garden (0.3898).

The CSI raw score, HFIAS Score and Income level correlations with coping strategies used by households are shown in Table 4.

The results in the study indicated that as the CSI and HFIAS scores increase, households relied more on consumption coping strategies (Rationing Strategies and Dietary Change Strategies). This is in line with a similar study on rural food insecurity by Mjonono (2009) on coping strategies in South Africa.

Weaker correlations were found in the case of the HFIAS Score, which may be attributed to the fact that the HFIAS relies more on perceptions with regard to household food insecurity. Spearman's correlation showed that food insecurity coping strategies were correlated significantly with CSI raw score, as well as HFIAS Scores. The study indicated that as CSI Scores/HFIAS Scores of households increase, households in this urban area rely on consumption soothing strategies (rationing and dietary change) such as relying on less expensive food, skipping meals, limiting portions sizes at meal times, and restricted consumption by adults in order to provide more food for smaller children.

Table 4: Coping strategy index (CSI) / HFIAS Score correlations with survival strategies used by households

\begin{tabular}{|c|l|c|c|c|c|c|}
\hline & \multicolumn{5}{|c|}{ Correlations with survival strategies } \\
\hline & Mean & Std Deviation & $\begin{array}{c}\text { Correlation with } \\
\text { CSI Score }\end{array}$ & $\begin{array}{c}\text { Correlation } \\
\text { with Income }\end{array}$ & $\begin{array}{c}\text { Correlation with } \\
\text { HFIAS Score }\end{array}$ \\
\hline 1 & Rely on less expensive commodities. & 1.9153 & 2.23065 & $0.784^{* *}$ & $-0.273^{* *}$ & $0.330^{* *}$ \\
\hline 2 & Purchased food on credit & 0.7017 & 1.26404 & $0.515^{* *}$ & $-0.211^{* *}$ & $0.323^{* *}$ \\
\hline 3 & Skip meals & 0.6203 & 1.23921 & $0.617^{* *}$ & $-0.232^{* *}$ & $0.326^{* *}$ \\
\hline 4 & Limited portion size at meal times & 1.1288 & 1.89441 & $0.818^{* *}$ & $-0.292^{* *}$ & $0.383^{* *}$ \\
\hline 5 & Buy necessities & 1.6881 & 1.97201 & $0.731^{* *}$ & -0.104 & $0.228^{* *}$ \\
\hline 6 & Stick to budget & 1.1051 & 1.60329 & $0.566^{* *}$ & -0.024 & 0.091 \\
\hline 7 & Maintain a food garden & 0.3898 & 0.93708 & $0.120^{*}$ & 0.078 & -0.071 \\
\hline 8 & $\begin{array}{l}\text { Borrowed food, or rely on help from a friend or } \\
\text { relative }\end{array}$ & 0.6949 & 1.16430 & $0.447^{* *}$ & $-0.141^{*}$ & $0.352^{* *}$ \\
\hline 9 & Sent household members to eat elsewhere & 0.2068 & 0.70563 & $0.337^{* *}$ & -0.076 & $0.200^{* *}$ \\
\hline 10 & $\begin{array}{l}\text { Restricted consumption of adults in order for } \\
\text { Small children to eat }\end{array}$ & 0.5424 & 1.46527 & $0.746^{* *}$ & $-0.224^{* *}$ & $0.286^{* *}$ \\
\hline 11 & Sent households members to beg & 0.1424 & 0.49494 & 0.120 & -0.023 & $0.119^{*}$ \\
\hline 12 & Gathered wild vegetables & 0.2508 & 0.79846 & $0.456^{* *}$ & -0.082 & $0.130^{*}$ \\
\hline
\end{tabular}

$\mathrm{P}=$ sig (2 tailed) results

* Sig. at $p<0.05$ ( $5 \%$ level of significance)

** Sig. at $p<0.01$ ( $1 \%$ level of significance)

Strong positive correlations ( $1 \%$ level of significance) between CSI and rely on less expensive food $(r=0.784, p<0.001)$, buying only necessities $(r=0.731, p<0.001)$, limit portions at meal times $(r=0.818, p<0.001)$, restricted consumption by adults $(r=0.746, p<0.001)$, skipping meals $(r=0.617, p<0.001)$, sticking to budget $(r=0.566, p<0.001)$ and purchasing food on credit $(r=0.515, p<0.001)$ as coping strategies were found. A weak positive correlation ( $5 \%$ level of significance) were 
found for maintaining a food garden $(r=0.120, p<0.005)$ while no significant correlation were found for sending family members to beg.

A positive correlation (1\% level of significance) between HFIAS Score and relying on less expensive food $(r=0.330, p<0.001)$, purchasing food on credit $(r=0.323, p<0.001)$, skipping meals $(r=0.326, p<0.001)$ and limiting portions at meal times $(r=0.383, p<0.001)$ as coping strategies were found. Non-statistically significant correlations were found with maintaining a food garden and sticking to budget.

A weak negative correlation (significant at 99 percent level) between the level of income of households and the following coping strategies: buying less expensive food $(r=-0.211, p<0.001)$, purchasing food on credit $(r=-0.211$, $p<0.001)$, skipping meals $(r=-0.232, p<0.001)$, limiting portions $(r=-0.292, p<0.001)$ and restricting consumption by adults $(r=-0.224, p<0.001)$ exist. This is an indication that as income of households increase they rely less on these coping strategies.

The positive correlations between consumption soothing strategies and CSI Scores and HFIAS Scores are an indication that food insecure households in urban areas restrict consumption with negative health consequences in urban areas. This underlies the argument that food insecure households in urban areas, to a large extent, depends on sufficient income, specifically in urban areas.

\section{Conclusion}

This study investigated the food security status of households in a low income urban neighborhood. The Coping Strategy Index (CSI) and Household Food Insecurity Access Scale (HFIAS) score were used to determine the status of households. Spearman's correlation coefficients were used to determine which coping strategies were used by food insecure households. The results showed that food insecurity in this urban low income neighborhood is at a scale that needs more attention in terms of analyses. As Maxwell (1998) argues "many governments in sub-Saharan Africa persist in thinking about urban food insecurity in terms of aggregate food supply to the cities, rather than the ability of poor households in urban areas to purchase food".

The results showed that households in urban areas opt for rationing of food and dietary changes. This is a very critical issue as it is associated with negative health consequences. Owing to the lack of available land in urban settings, urban food insecurity may pose a bigger challenge to policy maker's then rural food insecurity. The solution to this may be a comprehensive food insecurity strategy framework by government with a focus on urban areas.

The results reported by this study can be seen as a contribution to the growing body of knowledge on urban food insecurity. It is suggested that policymakers consider developing a comprehensive policy framework focusing on urban food insecurity.

\section{References}

Behrman, J.R. and Deolikar, A.B. (1988). Health and nutrition in Chenery, H. and Srivasan, T.N. ( Eds), Handbook of Development Economics. Vol. 1, Elsevier, Amsterdam.

Booysen F.(2004). The role of social grants in mitigating the socio-economic impact of HIVIAIDS: Evidence from the Free State Province. CSSR Working Paper No. 56. University of Cape Town: Cape Town.

Booysen, F. and Van Der Berg, S. (2005). The role of social grants in mitigating the socio-economic impact of HIVIAIDS in two free communities. South African Journal of Economics: 73: 545-563.

Christiansen, L. \& Boisvert, R. (2000). On Measuring Household Food Vulnerability: Case Evidence from Northern Mali. Working Paper. Department of Agricultural, Resources, and Managerial Economics, Ithaca, New York.

Coates, J. Frongillo, E.A. Rogers, B. L., Webb, P. Wilde, P.E. and Houser, R. (2006) Commonalities in the Experience of Household Food Insecurity across Cultures: What are Measures Missing? American Society of Nutrition.

Corbett, J. (1988) Famine and household coping strategies. World Development 16(9), 1099-1112.

Davies, S. (1993). Are Coping Strategies a Cop Out?. IDS Bulletin 24(4)60-72

De Haan, A. (1997). Urban poverty and its alleviation. IDS Bulletin 28 (2).

Deitchler, M., Ballard, T., Swindale, A., and Coates, J. (2010). Validation of a Measure of Household Hunger for Cross-Cultural Use. FANTA 2, USAID, Academy for Educational Development. Washington.Duflo, E. 2003. Grandmothers and granddaughters: oldage pensions and intrahousehold allocation in South Africa. World Bank Economic Review. 17(1) 1-25.

Frankenberg, T. (1992) Indicators and Data Collection Methods for Assessing Household Food Security, Part II, in S. Maxwell and T. Frankenberger, eds, Household Food Security: Cocepts, Indicators, Measurements. A Technical Review . UNICEF and IFAD. New York.

Human Sciences Research Council (HSRC) (2008). South African Social Attitude Survey. Pretoria.

Kirkland, M.K., Kemp, R.S. Hunter, L.M. and Wayne, T. (2011). Toward improved understanding of food security: A methodological examination based in rural South Africa. Working paper. IBS Population Program. University of Colorado. 
Manyamba, C., Hendriks, S. Chilonda, P. and Musaba, E. (2012). Factors contributing to inequality in food security in South Africa: implications for agricultural policy. Towards Carnegie III. A Conference held at the University of Cape Town from 3 to 7 September 2012.

Maxwell, D. \& Caldwell, R. (2008). The Coping Strategy Index, Field Methods Manuel, Second Edition.

Maxwell, S. (1996). Food security: a post-modern perspective. Food Policy, 21(2):155-70.

Maxwell, D., Ahiadeke, C. Levin, C. Armar-Klemesu, M. Zakariah, S. Lamptey, G.M. (1999) Alternative food-security indicators: revisiting the frequency and severity of coping strategies. Food Policy 24(4):411-429.

Maxwell, D. (1998). The political economy of urban food security in sub-saharan Africa. Food consumption and nutrition division. Discussion paper no. 41. International Food Policy Research Institute. Washington.

Migotto, B.D., Gero, C. and Kathleen, B. (2006). Measuring food security using respondents perception of food consumption adequacy. Reseach Paper No. 2006/88. United Nations University

Miller, C.M., Tsoka, M. and Reichert, K. (2011). The impact of the social cash transfer scheme on food security in Malawi. Food Policy, 36:230-238.

Mjonono, M., Ngidi, M., and Hendriks, S. (2009). Investigating household food insecurity coping strategies and the impact of crop production on food security using coping strategy index(CSI). 17 th International Farm Management Congress, July 2009.|llinois, USA.

Moser, C. (1996). Confronting Crisis: A Summary of Household responses to poverty and vulnerabilty in Four Poor Urban Communities. Environmentally Sustainable Development Studies and Mongraphs Series No. 7, The World Bank, Washington.

Oldewage-Theron, W.H., Dicks, E.G. and Napier, C.E. (2006) Poverty, Household food insecurity and Nutrition: Coping Strategies in an informal settlement in the Vaal Triangles, South Africa, Public Health, Sep, 120(9) 795-804

Radimer, K.L., Olson, C.M. and Campbell, C.C. (1990). Development of indicators to assess hunger. Journal of Nutrition, 120:15441548.

Radimer, K.L., Olson, C.M., Greene, J.C., Cambell, C.C. and Habicht, J.P. (1992). Understanding hunger and developing indicators to assess it in women and children. Journal of Nutrition Education, 24:36s-45s.

Ravallion, M. (2002) On the urbanization of poverty, Journal of Development Economics 68 (2): 435-442.

Samson, M.D., Rosenblum, C. Haarmann, D. Haarman, K. MacQuene and Van Niekerk. (2001). The socio - economic impact of workfare: welfare reform lessons from the United States and other international experiences. Research Paper No 26. Cape Town: Economic Policy Research Institute

Slabbert, T.J.C. \& Grobler, W.C.J. (2011) The impact of a proposed New Casino in the Vaal. Vanderbijpark.

Slabbert, T.J.C. \& Sekhampu, T.J. (2009). Bophelong: a socio-economic \& environmental analysis. Research report no.22. Vanderbijlpark: Vaal Research Group.

Snel, E. \& Staring, R. (2001). Poverty, migration, and coping strategies: an introduction. European Journal of Anthropology, 38:7-22.

STATS SA , (2011). Census. Pretoria: Government Printers. Pretoria: Government Printers.

STATS SA. (1995). The Income and Expenditure Survey of 1995

UNICEF. (1994). The Urban Poor and Household Food Security. . Policy and Project Lessons of how Government and the Urban Poor Attempt to Deal with Household Food Insecurity. Poor Health and Malnutrition. UNICEF, New York.

USAID. (1992). Policy determination, definition of food security. Washington. 